\title{
EL SISTEMA DE LICITACIONES CONTRACTUALES DE LAS DEFENSAS PENALES PÚBLICAS EN EL NUEVO PROCESO PENAL CHILENO
}

\author{
Ana María Morales $P^{*}$ \\ Flavio Galleguillos $C^{*}$.
}

\begin{abstract}
I. Introducción; II. El derecho de defensa. Fundamento normativo; III. El sistema chileno. Breve descripción; IV. Críticas al sistema de licitaciones: a) El sistema de licitaciones como renuncia al deber del estado de asegurar el derecho a la defensa pública. b) El sistema de licitaciones como vulneración del principio de igualdad ante la ley; V. Conclusiones.
\end{abstract}

\section{INTRODUCCIÓN}

El presente trabajo tiene por objeto hacer una reseña básica del marco legal y constitucional que recoge el derecho a defensa, y una descripción del sistema de defensa pública establecido en el país, a partir de la dictación de la Ley $\mathrm{N}^{\circ} 19.718$, que crea la Defensoría Penal Pública, estableciendo un sistema de prestación de defensa de carácter mixto.

Tomando como base lo anterior, se pretende elaborar una aproximación crítica al sistema de entrega de defensas penales públicas sobre la base de licitaciones contractuales a personas naturales o jurídicas de carácter público o privado, las que se fundan en que dicho sistema importaría, por una parte, una renuncia al deber del estado de asegurar el derecho a la defensa pública, y por la otra, una vulneración de la garantía constitucional de la igualdad ante la ley.

\section{EL DERECHO DE DEFENSA}

El derecho de defensa puede ser entendido como "la facultad del imputado de intervenir en el procedimiento penal que se dirige en su contra para poner en evidencia ya sea la falta de fundamento de la pretensión punitiva estatal o de cualquier circunstancia que la excluya o atenúe"1.

Este derecho encuentra su fundamento normativo en diversas fuentes formales. En primer lugar, a nivel constitucional, el artículo $5^{\circ}$ inciso segundo de la Constitución Política de la República establece como limitación al ejercicio de la soberanía "el respeto a los derechos esenciales que emanan de la naturaleza humana". Dicho precepto constitucional además establece que "es deber de los órganos del Estado respetar y

\footnotetext{
* Ana María Morales Peillard, Abogado de la Universidad de Chile, Colaboradora del Centro de Estudios de la Justicia de la Facultad de Derecho de la Universidad de Chile.

*Flavio Galleguillos Carmona, Licenciado en Ciencias Jurídicas y Sociales de la Universidad de Chile, Colaborador del Centro de Estudios de la Justicia de la Facultad de Derecho de la Universidad de Chile.

${ }^{1}$ Vásquez Rossi, J. E., "El proceso penal. Teoría y práctica", Editorial Universidad, Buenos Aires, 1986, pág. 49 .
} 
Galleguillos y Morales - Sistema de licitaciones de defensa penal pública

promover tales derechos garantizados por esta Constitución así como por los Tratados Internacionales ratificados por Chile y que se encuentren vigentes". Los pactos internacionales en los que se hace referencia al derecho de defensa son, entre otros, el Pacto Internacional de Derechos Civiles y Políticos y la Convención Americana de Derechos Humanos, que se refieren a este derecho en términos genéricos como el derecho que tiene todo imputado de un delito a defenderse personalmente o, si esto no le fuere permitido, elegir un defensor para que lo represente o asista, de comunicarse libre y privadamente con su defensor ${ }^{2}$, y el derecho a ser asistido por un defensor proporcionado por el Estado si el inculpado no se defendiere por sí mismo ni nombrare defensor ${ }^{3}$; estableciendo además otros derechos complementarios a éste e integrantes de la garantía del debido proceso, como por ejemplo, el derecho a ser oído, a controlar y controvertir la prueba de cargo, a probar los hechos que el mismo invoca para excluir o atenuar la reacción penal.

Asimismo, el artículo 19 N³ de la Constitución Política de la República, establece el imperativo legal de arbitrar "los medios para otorgar asesoramiento y defensa jurídica a quienes no pueden procurárselo por sí mismos". Esta fórmula, como ha señalado el profesor Raúl Tavolari, "no importa sino una decimonónica concepción de la defensa como una modalidad de caridad o gracia a los desposeídos"4.

A nivel legal la Ley N¹9.718, que crea la Defensoría Penal Pública, dispone en su artículo $2^{\circ}$ que "la Defensoría tiene por finalidad proporcionar defensa penal a los imputados o acusados por un crimen, simple delito o falta que sea de competencia de un juzgado de garantía o de un tribunal de Juicio Oral en lo Penal y de las respectivas Cortes, en su caso, y carezcan de abogado". Esta norma establece un criterio distinto a aquél sentado por la Constitución, toda vez que impone la obligatoriedad de la asistencia letrada a toda persona que carezca de abogado, y no tan solo a aquéllos que carezcan de recursos, ampliando de esta forma la extensión de la garantía.

En el Código Procesal Penal encontramos la norma del artículo $8^{\circ}$, que lleva como epígrafe el "Ámbito de la Defensa", señalando que "el imputado tendrá derecho a ser defendido por un letrado desde la primera actuación del procedimiento seguido en su contra".

Doctrinariamente, el derecho de defensa se desglosa en dos acepciones. La primera, comprende la llamada defensa material y la segunda, la defensa técnica.

\footnotetext{
2 Este derecho está consagrado en el artículo 8 letra d) de la Convención Americana de Derechos Humanos que establece el "derecho del inculpado de defenderse personalmente o de ser asistido por un defensor de su elección y de comunicarse libre y privadamente con su defensor" y en el artículo 14.3 letra d) del Pacto Internacional de Derechos Civiles y Políticos que establece el "derecho de toda persona acusada de un delito a hallarse presente en el proceso y a defenderse personalmente o ser asistida por un defensor de su elección; a ser informada, si no tuviera defensor, del derecho que le asiste a tenerlo, $y$, siempre que el interés de la justicia lo exija, a que se le nombre defensor de oficio, gratuitamente, si careciere de medios suficientes para pagarlo".

${ }^{3}$ Derecho contemplado en el artículo 8 letra e) de la Convención Americana de Derechos Humanos que establece "el derecho irrenunciable de ser asistido por un defensor proporcionado por el Estado, remunerado o no según la legislación interna, si el inculpado no se defendiere por sí mismo ni nombrare defensor dentro del plazo establecido por la ley".

${ }^{4}$ Tavolari, R., "Estándares básicos de actuación de la defensa penal" en Revista de Estudios de la Justicia, $\mathrm{N}^{\circ} 1$, año 2002, pág. 237.
} 
La defensa material consiste en el ejercicio de los derechos que la Constitución y las leyes le confieren al imputado durante el procedimiento ${ }^{5}$, y se ve plasmada en el inciso $2^{\circ}$ del artículo $8^{\circ}$ del Código Procesal Penal que señala: “el imputado tendrá derecho a formular los planteamientos y alegaciones que considerare oportunos, así como a intervenir en todas las actuaciones judiciales y en las demás actuaciones del procedimiento". Los derechos comprendidos dentro del concepto de defensa material han sido reunidos en tres grandes grupos: a) derechos de información: acerca de los hechos que se le imputan, los derechos que le asisten, los motivos de su detención; b) derechos de intervención en el procedimiento: a desvirtuar los cargos, a declarar, a solicitar el sobreseimiento en los casos que corresponda y; c) aquellos derechos que imponen un deber de abstención por parte de los órganos que intervienen en la persecución y el enjuiciamiento criminal, que incluyen el derecho a guardar silencio, a no declarar contra sí mismo, a no ser sometido a torturas ni a tratos crueles e inhumanos, a no ser juzgado en ausencia, a que la sentencia sea congruente con la acusación y la prohibición de la reforma en perjuicio. Estos derechos han sido recogidos en nuestro ordenamiento jurídico principalmente por la Constitución y el Código Procesal Penal, y constituyen garantías mínimas que debe abarcar el derecho de defensa en un Estado Democrático de Derecho.

La defensa técnica consiste en el derecho que tiene toda persona de ser asistida por un letrado desde la primera actuación en un procedimiento y comprende los siguientes aspectos: derecho de autodefensa, derecho al defensor técnico y derecho al defensor penal público ${ }^{6}$. La defensa técnica es considerada un elemento central de la institución del debido proceso legal y así lo ha establecido la jurisprudencia de la Corte Suprema de Estados Unidos, en casos tales como Powell vs. Alabama de 1935 y Gideon vs. Wainwright de 1963, en los cuales se reconoce el derecho de toda persona acusada por un delito a contar con la debida asistencia jurídica, debiendo ser ésta garantizada por el Estado a sus ciudadanos.

Todo lo anterior constituye el marco normativo y teórico que importa el derecho de defensa, constituyendo a su vez una garantía por la cual debe velar el Estado y una limitación a la función investigativa y jurisdiccional de éste, erigiéndose como una condición de legitimidad del proceso penal dentro de un Estado de Derecho. ${ }^{7}$

\section{EL SISTEMA CHILENO. BREVE DESCRIPCIÓN}

En primer lugar, antes de entrar a analizar el modelo de defensa penal adoptado por Chile, es necesario señalar que en el derecho comparado se presentan básicamente dos sistemas de defensa penal pública: aquél que se estructura sobre la base de una oficina pública bajo el alero de funcionarios estatales encargados de asumir la defensa obligatoria y aquél encargado a abogados privados que asumen la defensa a través de contratos firmados con el Estado y por la cual reciben un estipendio fijado estandarizadamente.

El sistema adoptado por la Ley N¹9.718, que crea la Defensoría Penal Pública, es de carácter mixto, toda vez que en él encontramos, por una parte, una oficina pública

\footnotetext{
${ }^{5}$ Horvitz, M. y López, J., Derecho Procesal Penal Chileno, Editorial Jurídica, tomo I, Santiago, 2003, pág. 227.

6 Caballero, A. y Stippel, J., "Manual de derecho internacional de los derechos humanos para defensores penales públicos”, en Centro de documentación Defensoría Penal Pública, N 1, Santiago, 2003, pág. 111.

7 Binder, A., "Crisis y transformación de la justicia penal en Latinoamérica", en Reformas procesales en América Latina, CPU, Santiago, 1993, pág. 85.
} 
Galleguillos y Morales - Sistema de licitaciones de defensa penal pública

integrada por funcionarios estatales letrados cuya labor es precisamente la de asumir la defensa de todos aquellos imputados que carezcan de abogado, desde la primera actuación del procedimiento; y por la otra, un sistema de prestación de defensa de carácter privado, la que es desplegada por personas naturales o jurídicas de carácter público o privado a las cuales se haya hecho entrega de una determinada cartera de causas, mediante un proceso de licitación y adjudicación de fondos de carácter público.

El marco legal que regula las licitaciones está dado, en primer término, por la Ley No19.718. Además encontramos el Decreto N 495 de 2002 del Ministerio de Justicia que fija el reglamento de las licitaciones, la resolución $\mathrm{N}^{\circ} 38$ que establece las Bases Administrativas Generales, y las bases especiales establecidas para cada proceso de licitación por el llamado Consejo de Licitaciones de la Defensa Penal Pública, que es el cuerpo técnico colegiado encargado de cumplir las funciones relacionadas con el sistema de licitaciones de la defensa penal pública.

De acuerdo a la mencionada normativa, se licita un cierto número de causas que deberán ser asumidas por el contratado en un determinado territorio. El porcentaje de causas a licitar se calcula sobre un número específico señalado en las bases especiales de licitación.

Al igual que otros procedimientos concursales desarrollados por la administración, considera las siguientes etapas: llamado abierto y público a presentar ofertas; plazo para realizar consultas y solicitudes de aclaraciones a las bases; evacuación de respuestas a consultas, con incorporación de las mismas al pliego de bases; aperturas técnica y económica de carácter público; decisiones del procedimiento, adjudicación y rechazo de propuestas, adoptadas con fundamento, y un sistema de recursos.

Las propuestas son analizadas y seleccionadas por un Comité de Adjudicación Regional, el que tiene como principal objetivo evaluar a nivel regional las licitaciones a las que se convoquen para la prestación de la defensa. Dicho comité está integrado por representantes del Ministerio de Justicia, la Defensoría Nacional, académicos de la región y jueces con competencia penal.

La primera etapa de evaluación se realiza utilizando los llamados criterios técnicos de calificación: el apoyo administrativo (infraestructura de atención de usuarios, mecanismos de control interno, mecanismos y sistemas de registros, apoyo de personal administrativo de los oferentes); la permanencia y habitualidad en el ejercicio de la profesión en la región respectiva; la experiencia y calificación de los profesionales que postulan y; el número y dedicación de los abogados disponibles y las proposiciones adicionales que formule el proponente.

La segunda etapa utiliza el llamado criterio económico o criterio de menor precio promedio ponderado. Como se señala en el Manual de postulación a las licitaciones, emitido por la propia Defensoría Nacional, "la evaluación económica consiste en la atribución de precio promedio ponderado a cada una de las ofertas, mediante la suma de los valores resultantes de aplicar el ponderador a cada uno de los valores ofertados por el proponente para cada uno de los servicios. De acuerdo a los precios promedios ponderados ofertados se atribuirá mayor puntaje a la oferta de menor precio promedio ponderado y luego se ordenarán las ofertas conforme a los puntajes obtenidos". 
Estos dos porcentajes pasan a formar parte de una nómina única, asignándole un $40 \%$ del puntaje total a la evaluación económica y un $60 \%$ a la evaluación técnica. Aquellos proponentes que estén en los topes de dicha nómina serán los que obtengan las licitaciones.

Una vez concluido el proceso de licitación, la Defensoría Regional respectiva deberá elaborar una nómina o lista de abogados seleccionados.

En cuanto a los controles, los abogados licitados deberán atender a lo dispuesto en la Ley $\mathrm{N}^{\circ} 19.718$, que establece como mecanismos fiscalizadores los informes, las inspecciones, las auditorías externas y un sistema de reclamo.

El sistema de entrega de defensa penal a privados a través de fondos concursables adjudicados mediante licitaciones, como señala Carocca, no existe en ningún otro país ${ }^{8}, \mathrm{y}$ al parecer la decisión de adoptar dicha modalidad en el nuestro se basó principalmente en la positiva evaluación que se realizó por parte de los legisladores del modelo de licitaciones, el que ha sido prolíficamente utilizado en toda clase de contrataciones de carácter administrativo. Lo anterior, obviando una serie de críticas susceptibles de ser efectuadas a dicho sistema de contratación, como aquéllas que apuntan a generales irregularidades en los procesos de adjudicación dadas, por las desigualdades de los oferentes frente a los licitantes, vulnerando principios cardinales de la contratación administrativa como es el de la igualdad de los oferentes ${ }^{9}$; estableciendo procedimientos de evaluación de las ofertas generalmente engorrosos y sin un apego irrestricto a las bases administrativas; ausencia de control de los fondos entregados durante la ejecución misma de las prestaciones, entre otras falencias.

Al efecto, el organismo internacional denominado Transparencia Internacional, elaboró un informe que contiene un mapa de riesgos sobre las licitaciones públicas en Chile ${ }^{10}$, describiendo una serie de factores de vulnerabilidad de dicho sistema de contratación. Dicho informe señala, entre otros factores de riesgo, la existencia de una multiplicidad de reglas atingentes a la contratación administrativa, ausencia de políticas formales, posibilidad de cambio de reglas del juego durante la etapa de preparación de propuestas y en su ejecución, amplia discreción para imponer a las empresas competidoras requisitos de experiencia previa, falta de estudios previos o deficiente calidad o sesgo cuando se realizan, y ausencia de evaluaciones ex post a las licitaciones y medición del desempeño, entre otros.

\section{CRÍTICAS AL SISTEMA DE LICITACIONES}

a) El sistema de licitaciones como renuncia al deber del estado de asegurar el derecho a la defensa pública.

\footnotetext{
${ }^{8}$ Carocca, A., "La nueva defensa penal pública", en Nuevo Proceso Penal, Conosur, Santiago, 2000, pág. 417.

9 Sobre este punto, la Comisión de Expertos nombrada por el gobierno para revisar y evaluar la marcha y funcionamiento del nuevo sistema de enjuiciamiento criminal, señaló en su informe evacuado en Diciembre de 2003, que se podría configurar una situación de competencia desleal entre los profesionales privados y la Corporación de Asistencia Judicial, toda vez que estas corporaciones se financian con aportes tanto fiscales como municipales que les permitiría operar a costos bajo el nivel de equilibrio económico.

${ }_{10}$ Mapa de riesgos sobre licitaciones públicas en Chile, Transparencia Internacional. Santiago, Enero de 2002.
} 
Galleguillos y Morales - Sistema de licitaciones de defensa penal pública

El sistema de licitaciones adoptado para efectos de proporcionar la defensa penal pública fue propuesto en base a los resultados obtenidos por un estudio realizado por el "Instituto Libertad y Desarrollo", el que analizó la factibilidad de establecer un sistema de este tipo. Dicho estudio al parecer no fue precedido de un análisis doctrinario respecto de la procedencia de entregar el ejercicio de una garantía constitucional en manos de particulares, como la que involucra el derecho a la defensa.

Como se ha señalado anteriormente la defensa técnica comprende el derecho a la autodefensa, el derecho al defensor técnico y el derecho al defensor penal público. Este último comprende, por lo tanto, la protección del derecho a ser asistido por un defensor proporcionado por el Estado, si el inculpado no se defendiere por sí mismo ni nombrare defensor. Es en esta situación donde le corresponde intervenir al Estado, es decir, cuando el imputado no desea o no puede autodefenderse o designar un abogado privado para que asuma su defensa. En esa esfera el Estado debe ser capaz de ofrecer un servicio de calidad y eficiente de tal forma que la Defensa entregada por éste no sea una defensa de "segunda selección", sino la "concreción de una garantía fundamental del derecho de defensa, dejando a salvo, evidentemente, al interesado optar por la defensa privada" ${ }^{11}$.

Desde esta perspectiva, nosotros postulamos que el sistema de licitaciones contractuales no satisfacería dicho presupuesto, pues el entregar la defensa pública a los privados importaría la utilización de criterios de selección que operan con una lógica de mercado no aplicable a un derecho fundamental como el derecho de defensa, y que dicen relación con la maximización de los recursos y la reducción de los costos, debiendo adjudicarse las defensas a aquellos oferentes que presenten la oferta más económica. Todos esos criterios no se condicen con la sensibilidad que representa la protección de los derechos que pueden verse afectados por la intervención punitiva del Estado. A lo anterior, debe sumarse el establecimiento de un sistema fiscalización débil para el control de cumplimiento de los estándares de calidad establecidos por la propia Defensoría Penal Pública, como se explicará más adelante.

En el mismo orden de ideas, debería al menos surgir un cuestionamiento respecto de la entrega a particulares de un cometido esencial como puede ser considerado el derecho a la defensa pública. Sobre este punto, la doctrina publicista tradicionalmente ha distinguido entre las funciones estatales y los cometidos estatales. La función estatal correspondería a las distintas potestades jurídicas de un Estado, así, serían funciones estatales la constituyente, legislativa, jurisdiccional y administrativa. Cometidos serían, en cambio, las múltiples actividades o tareas que el derecho pone a cargo de entidades públicas. De esta forma, podrían ser entendidos como cometidos estatales el de la salud, la educación y la defensa pública. Estos cometidos pueden ser esenciales y no esenciales, siendo esenciales aquéllos que, por la naturaleza del interés público comprometido, el Estado se atribuye su ejercicio en forma exclusiva, en consecuencia, no podrán concurrir los particulares a satisfacerlos. En cambio, los cometidos no esenciales son aquéllos en que el Estado podrá actuar en libre concurrencia con los particulares. Pero, como señala Silva Cimma, "sobre cuáles cometidos se estimarán esenciales y cuáles no, es ésa una materia que competerá en único y último término resolver a la acción armónica de las distintas funciones del Estado preferentemente a la resolución del legislador"12.

\footnotetext{
${ }_{11}$ Ferrajoli, L., Entrevista sobre la defensa pública en "Defensa Pública" en Pena y Estado, No 5, año 5, Buenos Aires, año 2002, pág. 110.

12 Silva Cimma, E., Derecho Administrativo, Editorial Jurídica, Santiago, 1969, pág. 17.
} 
Tomando como base lo anterior, nosotros postulamos que el Derecho a la Defensa Pública debe ser considerado un cometido esencial privativo del Estado, toda vez que hay un interés público comprometido, el cual es el de evitar que se condenen a inocentes, el necesario equilibrio con el instituto de la acusación y respeto a los derechos humanos que pudieren verse afectados por la actividad punitiva del Estado, de tal manera que trascendería el mero interés particular de los imputados, debiendo el Estado contar con una política de defensa pública representada por un órgano como la Defensoría Penal Pública.

Lo anterior importa rediseñar el sistema de defensa como una obligación del Estado, como señala Stella Maris Martínez"13, "esta concepción importa asumir que la obligación del Estado hacia los ciudadanos que han sido víctimas de un delito es de igual entidad que su deber frente a los sujetos que han sido reputados como autores de una conducta ilícita. En el primer caso, deberá arbitrar un sistema de justicia eficiente que posibilite el acceso a la justicia y que asegure a la víctima una adecuada reparación por el perjuicio sufrido y si ello es funcional a los intereses del Estado, la sanción de quien sea judicialmente declarado responsable sea en base a criterios de culpabilidad. En el segundo, deberá garantizar no sólo un aparato judicial eficiente e imparcial, sino también un sistema de defensa operativo y sustancial [....]. Para que este paradigma se cumpla es fundamental asumir que la vigencia plena del estado de derecho exige que el interés del Estado en que no se condene a un inocente sea por lo menos equivalente al ímpetu que ese Estado ponga en la persecución de los culpables"14.

Desde esta perspectiva, coincidimos con Manzini, quien entiende la defensa como "una función de asistencia jurídica a favor de los derechos y demás intereses legítimos de un sujeto procesal, en la aplicación de una finalidad de interés público y no solamente para el patrocinio del interés particular"15. Así, Manzini entiende la función del defensor como un custodio del derecho y la justicia en cuanto estos valores puedan encontrarse lesionados o amenazados en la persona del imputado. Dicha visión podría ser parangonada a la enunciada a propósito de la función del Ministerio Público por Gössel, el que se refería a éste como "vigía de la ley"16 en el control de las afecciones ilícitas de derechos y garantías que pudieran producirse en las actividades de investigación.

En este mismo orden de ideas, Guarneri, "después de señalar que el concepto de defensa es correlativo y dialécticamente integrado al de acusación, dice que ambos institutos interesan directamente y derivan del poder del estado"17.

Desde otra perspectiva, es necesario mencionar una de las tendencias del derecho penal alemán que, a través de autores reconocidos como Goldschmidt y Roxin, recogidos en ensayos realizados por Soto Piñeiro, han introducido la noción que el derecho penal "es a la vez un medio de protección y una amenaza para los derechos individuales; lo que

\footnotetext{
13 Defensora Pública Oficial ante la Corte Suprema de Justicia de la Nación Argentina.

14 Martínez, S. M., "Defensa Pública, Derecho del Pueblo" en Defensa Pública, Revista Pena y Estado, Año 5, N 5, Buenos Aires, año 2002, pág. 56.

15 Manzini, V., autor citado por Vásquez Rossi, J. E. en La Defensa penal, Editorial Rubinzal- Culzoni, Buenos Aires, págs. 162 y 163.

16 Gössel, K., "Reflexiones sobre la situación del ministerio público en el procedimiento penal de un estado de derecho y sobre sus relaciones con la policía", en Doctrina penal, pág. 654.

17 Guarneri autor citado, Vásquez Rossi, J. E. en "La Defensa penal”, op. cit., pág. 163.
} 
Galleguillos y Morales - Sistema de licitaciones de defensa penal pública

Silva Sánchez llama el carácter paradojal del Derecho Penal y, por ende, del Derecho que salvaguarda derechos individuales, lesionando derechos individuales. Como lo apuntó antes que ningún otro en nuestro medio el Profesor Bascuñan Rodríguez, el Derecho Penal es una amenaza para los derechos individuales y, por ende, está sometido a todo un régimen de garantías para el ciudadano y de restricciones para el Estado que se manifiestan antes que nada en el ámbito procesal penal"18.

Este carácter paradojal, nos llevaría a señalar que la defensa desempeñaría una función de carácter análoga a aquélla que le corresponde al Ministerio Público a través del ejercicio principalmente de la acusación. De esta forma no resultaría congruente establecer estatutos diferentes entre ambas instituciones, como aquéllos que dicen relación con la jerarquía normativa de su establecimiento, así, el Ministerio Público es creado en virtud de una ley orgánica constitucional, mientras que la Defensoría Penal es regulada mediante una ley ordinaria; a la dependencia orgánica, de esta forma, mientras que el Ministerio Público es un organismo autónomo de los demás poderes del Estado, la Defensoría es un servicio público sometido a la supervigilancia del Presidente de la República, a través del Ministerio de Justicia; al presupuesto asignado, siendo el presupuesto de la Defensoría equivalente a tan sólo un tercio del aquél entregado al Ministerio Público; y, finalmente, entregar parte de la función de defensa pública a los particulares, pretendiendo que dicha defensa licitada absorba la mayoría de las causas ingresadas. Como lo señala Soto Piñeiro en forma irónica, "¿cabe preguntarse simplemente qué fundamento de fondo existiría para no aplicar el mismo sistema (de licitación) al Ministerio Público?”. ${ }^{19}$

En casos como Estados Unidos, señala Horvitz, "la existencia de una oficina de defensoría organizada en términos similares a las fiscalías, es considerada como indispensable para garantizar la igualdad entre ambas partes y cumple una función de contrapeso "simbólico", frente al enorme poder del Ministerio Público americano"20.

\section{b) El sistema de licitaciones como vulneración del principio de igualdad}

Esta crítica está centrada en poner en evidencia la forma en que el sistema de licitaciones puede llegar a afectar garantías básicas reconocidas constitucionalmente.

En primer lugar, el sistema de licitaciones está diseñado para absorber la mayoría de los casos penales que se susciten en el nuevo sistema. Es decir, la mayoría de las defensas deberían ser adjudicadas a particulares a través de dichas licitaciones. Si consideramos el carácter selectivo del sistema penal, debemos concluir que los principales beneficiarios del nuevo sistema de defensa deberían ser aquellos sectores más carenciados de la sociedad, quienes son la clientela tradicional del ejercicio del ius puniendi estatal y que encontrarían en él una defensa de sus derechos y garantías de una calidad superior a la que recibían bajo el antiguo sistema, a través de los programas de asistencia gratuita, proporcionados por la Corporación de Asistencia Judicial y los abogados del turno.

\footnotetext{
18 Soto, M., "En torno a los denominados estándares básicos que debe cumplir la defensa penal pública", Revista de Estudios de la Justicia, $\mathrm{N}^{\circ} 1$, año 2002, pág. 219.

19 Ídem, pág. 218.

${ }^{20}$ Horvitz, M. y López, J., Derecho Procesal Penal Chileno, op. cit., pág. 251.
} 
En la actualidad, el presupuesto asignado anualmente por causa licitada corresponde a aproximadamente la suma de $\$ 96.282^{21}$. Con dicho estipendio asignado por causa a licitar, resultaría lógico especular que los grandes y más prestigiosos estudios penalistas presentarán escaso interés en participar en el nuevo sistema vía licitación, quedando éste entregado en mano de estudios jurídicos de menor renombre y recursos, los que necesariamente deberán abaratar sus costos de carácter humanos y técnicos para efectos de obtener ganancias.

En el informe emitido en Diciembre de 2003 por la Comisión de Expertos, nombrada por el gobierno para revisar y evaluar la marcha y funcionamiento del nuevo sistema de enjuiciamiento criminal, se señala que según las cifras disponibles "los llamados a licitación sólo han sido capaces de cubrir, aproximadamente el $70 \%$-como promediode los servicios demandados. De esta forma, ha existido un nivel de fracaso que es necesario revertir, para lo cual es menester diagnosticar apropiadamente las causas de este bajo interés en ofrecer servicios"22. A nuestro juicio, estos resultados se deben fundamentalmente a la falta de incentivo económico para los potenciales oferentes de esta prestación.

En este mismo orden de ideas, quienes postulen a las licitaciones deberán procurar adjudicarse el mayor número de causas permitidas por las bases, para que les resulte económicamente atractiva su participación. Tomemos como ejemplo el caso de la novena región, en que el máximo anual establecido por defensor es de 384 causas ${ }^{23}$. Considerando, además, que respecto de los defensores penales no se establece la regla de la exclusividad ${ }^{24}$, permitiéndose el libre ejercicio de la profesión en todas aquellas materias que escapen al ámbito penal, estimamos que podría verse afectada la calidad de las defensas prestadas por los defensores, como consecuencia de una sobrecarga de trabajo en la medida que no se exija una mínima dedicación de horas mensuales a sus causas licitadas.

Sobre este mismo punto, no coincidimos con lo señalado por la Comisión de Expertos, que sostiene que una de las razones que explicarían el bajo interés en participar en las licitaciones sería la prohibición contenida en las bases de licitación de participar en defensas penales en todo el territorio nacional, proponiendo que dicho impedimento debiera restringirse a la respectiva región. Estimamos que dicha propuesta afectaría, aún más, la calidad de las defensas licitadas y no representa una solución efectiva al problema, toda vez que los estudios que poseen cobertura a nivel nacional son una minoría y son precisamente los estudios más importantes, quienes, a nuestro juicio, no tendrían mayor interés en participar por el escaso atractivo económico que representan las licitaciones.

El problema, a nuestro entender, radica en que los servicios licitados están concebidos de tal forma que constituyan un ingreso marginal de los interesados, como lo afirma la propia comisión. Dicha concepción, lógicamente va en desmedro de la calidad de la defensa, redundando en una suerte de defensa de "segunda selección".

\footnotetext{
${ }^{21}$ Formulario de presentación de propuesta económica. Defensoría Penal Pública. IX Región. 2003.

22 Obra citada, pág. 31.

${ }^{23}$ Formulario de presentación de propuesta económica, op. cit.

${ }^{24}$ A diferencia de los funcionarios del Ministerio Público.
} 
Galleguillos y Morales - Sistema de licitaciones de defensa penal pública

Desde otra perspectiva, es necesario señalar que la posibilidad de desarrollar investigaciones paralelas a la del Ministerio Público se vería bastante diluida, tomando en cuenta el presupuesto asignado por causa. En este orden de ideas, Horvitz señala que "queda sin resolver la cuestión sobre las posibilidades de financiar una investigación técnica paralela y eficiente sin recurrir al Ministerio Público y sus auxiliares. [...] En Chile, y en el caso de los abogados que presten el servicio de defensa penal pública mediante licitaciones, el único criterio que se refiere a este punto y que debe ser considerado a la hora de adjudicar el fondo, es el previsto en la letra e) del artículo 46 de la LDPP, esto es, el "apoyo administrativo de los postulantes". Este criterio pareciera referirse únicamente al apoyo material y personal interno de cada oficina, es decir, no serviría para satisfacer los requerimientos procesales de las causas, como por ejemplo, la contratación de un investigador privado o perito. En consecuencia, para el defensor que no pueda asumir el costo de tales diligencias, las restantes opciones son: la solicitud de diligencias al Ministerio Público, quien estaría obligado a efectuarlas en virtud del principio de objetividad, y la solicitud de exención total o parcial del pago de la remuneración al perito, con todas las desventajas que las mismas acarrean". ${ }^{25}$

Lo anterior podría traer aparejada la asunción de un rol más bien de carácter reactivo por parte de los defensores, frente a las actuaciones del Ministerio Público, dejando de lado por completo una actividad de carácter investigativa en forma autónoma, pudiendo lo anterior llegar a afectar por completo la materialización de una teoría del caso $^{26}$.

Como consecuencia de lo antes, señalado se puede postular que el sistema de licitaciones atenta contra el principio de igualdad consagrado constitucionalmente, toda vez que los imputados que carezcan de recursos económicos tendrán que conformarse con el servicio que presten los defensores licitados, en los términos que señalamos, con una defensa básica de carácter reactivo, concebida como un ingreso residual para los prestadores de dicho servicio. Mientras que los imputados que cuenten con recursos podrán optar por entregar su defensa a los estudios que estimen conveniente para sus intereses o a la Defensoría Penal Pública, mediante el pago de honorarios. Desde esta perspectiva, se podría señalar que se mantendrían las condiciones estructurales de desigualdad en el acceso a la justicia entre aquellos imputados que cuenten con medios económicos suficientes para costear la contratación de estudios jurídicos de su preferencia frente a los imputados que carezcan de dichos recursos.

En este mismo sentido, Stella Maris Martínez sostiene que "sería absurdo desconocer que la clientela masiva del sistema penal está conformada por pobres cada vez más pobres; la selectividad innata al funcionamiento de los distintos segmentos y su privilegiado rol de controlador social hacen que atrape en su red casi exclusivamente a

\footnotetext{
${ }^{25}$ Horvitz, M.I., "Estándares de prestación de Defensa Penal Pública" en Revista de Estudios de la Justicia, $\mathrm{N}^{\circ} 1$, año 2002, pág. 190.

${ }^{26}$ Esta misma crítica ya ha sido planteada respecto del servicio prestado por la Defensoría Penal Pública en el informe denominado "Evaluación de la Reforma Procesal Penal. Estado de una reforma en marcha" elaborado por el Centro de Estudios de la Justicia de las Américas y el Programa de Justicia Criminal de la Universidad Diego Portales. Haciéndonos cargo de esta crítica, nosotros consideramos que ella es válida en atención al diseño actual del servicio de la Defensoría Penal Pública, pero dichas críticas podrían ser superadas con el fortalecimiento de este organismo a través de un rediseño institucional que lo erija como una oficina pública homologable al Ministerio Público, dotándola de mayores recursos humanos y materiales para otorgar cobertura a toda aquella clientela que no quiera o no pueda optar por una defensa privada.
} 
marginados. Sólo una defensa a cargo del Estado garantizará a estos individuos un servicio eficiente. Todas las experiencias que, en el ámbito latinoamericano, intentaron convocar a los abogados con ejercicio libre de la profesión para que, ya sea como un servicio comunitario o recibiendo una remuneración que era siempre muy inferior a sus expectativas se hicieran cargo de defender a los indefensos, fracasaron estrepitosamente"27.

Como una forma de evitar eventuales deficiencias en la prestación del servicio de defensa pública, se han fijado estándares mínimos de calidad en dicha prestación. Al efecto, el Defensor Nacional, mediante Resolución Exenta N³95, estableció estándares básicos para el ejercicio de la defensa penal pública, aplicables a las defensas entregadas vía licitación. Los problemas que presenta dicho oficio son que en primer lugar, establece estándares más bien de carácter ético, difíciles de medir cuantitativa y cualitativamente, dejando parcialmente de lado el establecimiento de estándares que digan relación con las destrezas técnicas y profesionales exigibles, vinculadas con factores tales como la carga de trabajo, conductas procesales exigibles en cada etapa del procedimiento y responsabilidades administrativas del abogado ${ }^{28}$. Si bien existe consenso en que a través de la dictación de estos estándares no se persigue sobrerregular la actuación de los defensores restándoles la necesaria autonomía en el desarrollo de su labor, no es menos cierto que dichos estándares entendidos como "niveles de comportamiento profesionales (mínimos o máximos) exigidos en el desarrollo de las defensas procesales penales"29 deberían fijar pautas objetivas del desempeño del defensor, toda vez que estos "constituirán indispensables elementos objetivos de análisis de la calidad del servicio profesional dispensado. Por este camino, en consecuencia, se abrirán vías de efectivo control público del trabajo de los letrados en el ámbito procesal penal"30.

Otro problema dice relación con el sistema de sanciones asociadas al incumplimiento de dichos estándares. Al respecto, el artículo 71 de la Ley N¹9.718, en relación con los artículos 69 y 70 de dicha ley, establece que el defensor incurre en responsabilidad en aquellos casos que su defensa no fuera satisfactoria de acuerdo a los estándares definidos por el Defensor Nacional, en cuyo caso procederá la aplicación de multas establecidas en los respectivos contratos. Sin embargo, no contempla la posibilidad de poner término a los contratos por esa causal, lo que parece bastante criticable si se considera que estos contratos administrativos están concebidos para ser renovados cada tres años. La única solución para que el defensor negligente abandone una determinada causa es que el imputado solicite su reemplazo, exigiendo por lo tanto la presencia de un imputado con cabal conocimiento de sus derechos, del estado de su causa y de las formas de enfrentar su defensa.

De todo lo antes señalado se advierte la posibilidad de que el sistema de licitaciones de defensas penales no asegure un servicio de calidad a sus usuarios, no sólo por mantener la desigualdad estructural en razón de los recursos económicos con que cuenten los imputados, sino también por el hecho de que los estándares básicos para el ejercicio de las defensas penales no establecen pautas objetivas que permitan un control

\footnotetext{
${ }^{27}$ Martínez, S.M. en “Defensa Pública...”, op. cit., pág. 56.

${ }_{28}$ Horvitz, M.I., "Estándares de prestación de Defensa penal pública" en Revista de Estudios de la Justicia, No 1 , año 2002, pág. 192.

29 Tavolari, R., "Estándares básicos de actuación de la defensa penal", op. cit., pág. 237.

30 Ídem
} 
Galleguillos y Morales - Sistema de licitaciones de defensa penal pública

eficiente de la calidad de las defensas licitadas, vulnerándose de esta manera la garantía constitucional consagrada en el artículo $19 \mathrm{~N}^{\circ} 2$ de la carta fundamental, que establece la igualdad ante la ley y señala que "en Chile no hay persona ni grupo privilegiado".

\section{CONCLUSIONES}

Del análisis realizado en el presente trabajo acerca del sistema de defensa penal pública establecido en Chile por la Ley $\mathrm{N}^{\circ} 19.718$, y del examen de la garantía constitucional del derecho a la defensa, aparece en relieve el carácter desigual que presenta el sistema de licitaciones, en la medida que los usuarios del sistema no tendrán asegurada la prestación de una asistencia letrada de calidad por carecer de recursos económicos suficientes para ello.

Por otra parte, el sistema de licitaciones representa una renuncia al deber el Estado de asegurar el derecho a la defensa pública, toda vez que éste debería ser entendido como una función pública encaminada a proteger un interés público, y no tan solo el interés particular del imputado.

Lo anterior resulta criticable tomando en consideración el ya mencionado carácter paradojal del derecho penal en el sentido de protección y afección de garantías constitucionales que conlleva el ejercicio del ius puniendi estatal.

En vista de lo anterior, se podría postular el establecimiento de un sistema de defensa penal pública, exclusivamente asumido por el aparato estatal a través de un servicio de Defensoría Penal Pública que pueda ser homologado, en cuanto a su naturaleza jurídica, al Ministerio Público como organismos que velan por la eficacia del derecho. Y que actúe como un contrapeso al ejercicio del poder punitivo del Estado, por parte del aparato de persecución pena encabezado por el Ministerio Público.

Bibliografía Consultada

BAYTELMAN, ANDRÉS, Evaluación de la Reforma Procesal Chilena, trabajo conjunto realizado por el Centro de Estudios de la Justicia de la Universidad de Chile y el Centro de investigaciones Jurídicas de la Universidad Diego Portales, Santiago, 2002.

BAYTELMAN, ANDRÉS y MAURICIO DUCE Evaluación de la Reforma Procesal chilena. Estado de una reforma en marcha", trabajo conjunto realizado por el Centro de investigaciones Jurídicas de la Universidad Diego Portales y El Centro de Estudios de Justicia de las Américas, Santiago, 2003.

BINDER, ALBERTO, “Crisis y transformación de la justicia penal en Latinoamérica”, en Reformas procesales en América Latina, CPU, Santiago, 1993.

CABALlERO, A. Y STIPPEL, J. , "Manual de derecho internacional de los derechos humanos para defensores penales públicos", Centro de documentación Defensoría Penal Pública, Nº 1, Santiago, 2003.

CAROCCA, ALEX, "La nueva defensa penal pública", en Nuevo Proceso Penal, Editorial Conosur, Santiago, 2000.

FERRAJOLI, LUIGI, Entrevista sobre la defensa pública en "Defensa Pública", revista Pena y Estado, N 5 , año 5, Buenos Aires, año 2002.

GOSSEL, KARL-HEINZ, "Reflexiones sobre la situación del Ministerio Público en el procedimiento penal de un estado de derecho y sobre sus relaciones con la policía” en Doctrina Penal No16, 1981. 
REJ - Revista de Estudios de la Justicia - No 4 - Año 2004

HORVITZ, MARIA INÉS y LÓPEZ, JULIÁN, Derecho Procesal Penal Chileno, tomo I, Editorial Jurídica, Santiago, 2002.

HORVITZ, MARIA INÉS, "Los sistemas de defensa penal pública: tres modelos del derecho comparado (Estado de Wisconsin (E.E.U.U.), Francia y Costa Rica), inédita, CDJ/CPU, Santiago, 1993.

HORVITZ, MARIA INÉS, "Estándares de prestación de defensa penal pública" en Revista de Estudios de la Justicia $\mathrm{N}^{\circ}$ 1, Santiago, 2002.

MACIA, RAMÓN, Sistemas de Proceso Penal en Europa, Editorial Cedecs, Barcelona, 1998.

MARTÍNEZ, STELlA MARÍS, "Defensa Pública, Derecho del Pueblo" en Defensa Pública, Revista Pena y Estado, Año 5, N 5, Buenos Aires, año 2002.

SILVA, ENRIQUE, Derecho Administrativo, Editorial Jurídica, Santiago, 1969.

SOTO, MIGUEL, "En torno a los denominados estándares básicos que debe cumplir la defensa penal pública", Revista de Estudios de la Justicia, N¹, Santiago, 2002.

TAVOLARI RAUL, "Estándares básicos de actuación de la defensa penal" en Revista de Estudios de la Justicia, $\mathrm{N}^{\circ}$ 1, Santiago, 2002.

VÁSQUEZ ROSSI, J. E., La Defensa penal, Editorial Rubinzal- Culzoni, Buenos Aires.

VÁSQUEZ ROSSI, J. E., El proceso penal. Teoría y práctica, Editorial Rubinzal- Culzoni, Buenos Aires.

ZÚÑIGA, ALEJANDRA, "El interés público del derecho a la vida", Cuadernos de análisis jurídicos $\mathrm{N}^{\circ} 14$ de la Escuela de Derecho de la Universidad Diego Portales, Santiago, 2002. 